\title{
On Obstacles of Metaphor Translation from Perspective of Culture
}

\author{
Ke-yu $\mathrm{He}^{1}$ \\ ${ }^{1}$ School of Foreign Language, Sichuan University of Science \& Engineering, Zigong, Sichuan, China \\ Correspondence: Ke-yu He, School of Foreign Language, Sichuan University of Science \& Engineering, Zigong, \\ Sichuan, China. E-mail: 470192133@qq.com
}

$\begin{array}{ll}\text { Received: December 26, } 2016 & \text { Accepted: February 10, } 2017 \quad \text { Online Published: February 28, } 2017 \\ \text { doi:10.5539/ells.v7n1p126 } & \text { URL: http://doi.org/10.5539/ells.v7n1p126 }\end{array}$

\begin{abstract}
Translating is a complex and fascinating task, as Richards (1965) once claimed that translating is probably the most complex type of event in the history of the cosmos. In the development of modern translation theories, there is a tendency that culture is introduced into this field. Translating becomes more complex for it has been defined as a cross-cultural communication event, and it involves not only two languages but also two cultures. This shift from emphasis on linguistic transfer towards emphasis on cultural transfer naturally exists in the translation of metaphor. Metaphor is not only an important figure of speech, but also a cognitive means of human mind. The people with different means of thinking have different cultures. The metaphorical language used by people must be fully saturated with culture peculiar to it. So because of the influence of cultural factor, the translation of metaphors becomes the most important particular problem. The paper discusses the reasons for the difficulties of metaphor translation, and summarizes several obstacles of it.
\end{abstract}

Keywords: obstacles, metaphor, culture, translation

\section{Introduction}

Language is the principal means whereby we conduct our social lives. When people use it to communicate, language is always bound up with culture closely in various complex ways. Firstly, the words people utter not only refer to common experience, but also reflect their author's attitudes, beliefs and their point of view when communication is going on. So, language expresses cultural reality. Secondly, members of a community or social group do not only express experience, and they also create experience through language. The way in which people use the spoken, written, or visual medium creates meanings that are understandable to the group they belong to. Thus, language embodies cultural reality. Lastly, language is a system of signs that is seen as having a cultural value. So, we can say that language symbolizes cultural reality.

Susan Bassnett, an English scholar of Translation studies, says: "The questions that are generally accepted as relevant and important enough to be as bed in the field of translation studies are very different now from what they were twenty years ago". (Bassnett \& Lefevere, 2004, p. 1) What he said indicates clearly that current studies in translating have changed. This is a clearest indicator. Another indicator of change is that "translation studies have now come to mean something like "anything" that (claims) to have anything to do with translation". (ibid: 1) These important features of sociological settings have been attracted to translation.

In 1970s, the new orientation in translation study begins appearing and it focuses on culture exchange instead of linguistic exchange. Christian Nord defined translation as intercultural communication. Translating is an operation between two cultures, so it can be called intercultural cooperation. Therefore, it is reasonable to even give a new term for translation as "transculturation".

According to the contemporary views of metaphor, metaphor functions not only as a figure of speech, but also as a cognitive device, as Lakoff and Johnson say that the concept is metaphorically structured, and the activity is metaphorically structured. Therefore, the language is metaphorically structured. Metaphor is conceptual system to recognize new thing and understand an object thoroughly. From this view of point, we can say that metaphor has become an indispensable way to know the world. In this respect, it is of great significant to deal with the translation of metaphor. What is more, metaphor is culture-specific, which deepens the difficulty of metaphor translation. Therefore, it is quite necessary to achieve the task of the studies on the translation of metaphor from the angle of culture. So because of the influence of cultural factor, the translation of metaphors becomes the most important particular problem (Newmark, 2001a). However, up to now, there is no one who has researched 
on how to find the reasons for metaphor translation and obstacles in translating metaphor in theory.

In a word, we can say that language expresses and creates cultural reality in certain aspects. Hence, language is endowed with cultural characteristics, and language plays the most important role in the transfer of culture. Nowadays, more and more people think language is an essential part of culture and culture influences language by way of symbols and rules as well as the perception of the universe. So, we can say that culture and language are interactive, and both of them are quite significant. Thus, in order to establish the theoretical system of metaphor translation, it is significant to research on reasons for the difficult of metaphor and obstacles in translating metaphor form the perspective of culture.

\section{Metaphor and Culture}

\subsection{What is Metaphor}

Metaphor, as a figure of speech, is unavoidably associated with culture due to the relationship of language and culture. As far as the theme of the thesis is concerned, it is indispensable to make clear the relationship between metaphor and culture. Above all, the author focuses on the discussion of metaphor.

What is metaphor? It seems to be a simple question and easy to answer it. But, in fact, up to now, no one can give a perfect and distinctive answer.

The word "metaphor" comes from the Greek word "metaphora". The root of "meta" means "across", and "pherein" means "carrying". The combined word refers to a particular linguistic process through which the characteristics of a certain object could be transferred to another, to the effect that the second object could be taken as the first one (Hawkcs, 1992, p. 1).

The Oxford Advanced Learner's English-Chinese Dictionary (4th edition) defines metaphor as (example of the) use of a word or phrase to indicate something different from (through related in some way to) the literal meaning as in "I'll make him eat his words" or "she has a heart of stone". In Webster's Dictionary of the English Language Unabridged (Encyclopedic edition) metaphor is "a figure of speech in which one thing is likened to another, different thing by being spoken of as if it were that one: implied comparison, in which a word or phrase ordinary and primarily used of one thing applies to another (e.g., screaming headlines, all the world's stage;) distinguished from simile." Peter Newmark defines metaphor as:

"Any figurative expression: the transferred sense of a physical word; the personification of an abstraction, the application of a word or collocation to what it does not literally denote, i.e., to describe one thing in terms of another. [...] Metaphors may be "single"-viz, one-word- ...or "extended" (a collocation, an idiom, a sentence, a proverb, an allegory, a complete imagination text." (2001b)

In analyzing the above definitions, we can get several important points of the characteristics of metaphor. Firstly, the creation of metaphor is based upon the psychological activity of association of one thing with another one, and those forms might be similarity, resemblance or comparison, etc. It is not only a linguistic phenomenon but also a psychological process. "Metaphor is in fact based on a scientific observable procedure; the perception of a resemblance between phenomenon, i.e., object or processes." (Newmark, 2001a) Secondly, metaphor has been expanded from word into sentence, even a bigger structure such as a poem and a text. A word can be a metaphor; an idiom can be a metaphor; a sentence can be a metaphor; a poem can also be a metaphor, etc.

The scope on the study of metaphor has been enlarged. With the development of the further subdivision of science and technology, it has been explored from the perspective of semantics, pragmatics and philosophy, and there is a tendency of using a cognitive and interdisciplinary approach to the study of metaphor. In the narrowest sense, metaphor is regarded as a rhetorical device, which covers all figures of speech except simile. In a broader sense, metaphor is often understood as not only a kind of figure of speech, but also thought of people, a cognitive device. As a figure of speech, the purpose of metaphor is to liven up texts, to make them more colorful dramatic and witty, notoriously in journalism.

In order to deal with metaphor translation, it is indispensable to have clear understanding of some basic terms about metaphor, the following terms are: (Newmark, 2001b)

Image: the picture conjured by the metaphor, which may be universal, cultural, or individual;

Object: what is described or qualified by the metaphor;

Sense: the literal meaning of the metaphor, the resemblance overlapping object and image;

Metaphor: the figurative word used, which may be one-word, or extended over any stretch of language from a collocation to the whole text; 
Symbol: a type of cultural or conventional signs where a material object represents a concept.

\subsection{Relationship between Culture and Metaphor}

Through the above analysis, we know that language is a social phenomenon and the life of human society is woven around it so that language can only be understood in terms of the special culture. Language and culture hence interact so closely with each other that we cannot separate them. On one hand, language is an integral part of culture and plays a very important role in it. On the other hand, language is influenced and shaped by culture. We often regard words as the first articulation of meaning, and since all symbols are metaphors or metonyms replacing the objects, all words therefore are metaphorical. Language is structured metaphorically; language itself is a metaphorical web. Thus, culture influences upon language are obvious on metaphor. In other words, Metaphors acquire their associative meanings from native literature, local customs, religions, world views, folk believes, senses of value, modes of thinking, and so on, which sometimes are clearly different and sometimes overlap in different cultures.

The relationship between cultural disparities and associative meaning of a metaphor might be reflected in the following three ways:

1) An image has its counterpart in the target language. It has the same referential meaning, but its associative meaning is unique to the source language and culture.

In Chinese culture, tiger is regarded as the king of the beasts that has the positive connotation of being majestic; it is thought highly of, as can be seen from in some expressions like “鼠头蛇尾” (a tiger's head and a snake's tail一a fine start and poor finish), “虎威” (powers of a general), “狐假虎威” (the fox borrows a tiger’s terror), “骑虎难下” (he who rides a tiger is afraid of dismounting一irrevocably but unwillingly committed), “虎口拔牙” (pull a tooth from the tiger's mouth), “老虎屁股摸不得” (like a tiger whose back side no one dares to touch-dare and greatest danger), etc. In English culture, however, tiger is considered commonly as a kind of fierce and powerful animal and no other associative meanings are evoked.

2) An image has its counterpart in the target language-culture, which has the same referential meaning but different metaphorical meaning.

For example, in Chinese culture, vinegar may evoke jealousy relating to the love as the expression “吃醋”, while, in English culture, vinegar often connects with the description of bitterly sarcastic language, being unhappy or ill-tempered. Another example is dragon. In Chinese culture, dragon is canonized as embodiment of Chinese people. Its associative meanings are often related to the senses of power, good and success. There are many expressions, such as: “龙颜”; “龙驹风倠”; “龙飞凤舞”; “龙风呈祥”; “望子成龙” etc. But, in English, dragon is fierce and cruel animal, which is commonly used to signify bad people and bad actions. Therefore, these examples indicate that the differences reflect in metaphors with rich cultural association as well as in the degrees of commendatory term and derogatory term. In a word, it is clear that different cultures bear different tastes on the same image used in metaphors and provides different value judgment on their appreciation.

3) The metaphor in the source language-culture whose reference unfamiliar with readership of the target culture carries the pragmatic meaning.

In classical Chinese works, there are many special expressions that are empty ones in the western works. For example，“得陇望蜀” (cover shu after getting long一have insatiable desires), “身在曹营心在汉” (metaphorically means being out of mind), “三个臭皮匠顶个诸葛亮” (three cobbles with their wits combined surpass Zhuge Liang the master mind - the wisdom of the masses exceeds that of the wisest individual).

The effective interlingua communication is always possible because of the openness and fundamental similarities shared by different languages and cultures. That is to say, there exist cultural universals that result from the same physical make-up and certain similar living environments. Therefore, there are some common features shared by language that result from cultural universal. And it is these languages and cultural universals that lay the foundation of translatability.

\section{Relationship among Translation, Culture and Metaphor}

In a word, metaphor is not only a rhetoric device to color language, and it but also sharpens language so as to describe the life of the world or the mind more accurately and precisely than literal language does.

Though there are many discussions about metaphor in the field of literary criticism and rhetoric, the translation of metaphor has been largely neglected by translation theorists. Menachim Dagut took up the subject in 1976 in an essay entitled "can "metaphor" be translated?" which initiated a formal discussion of the subject. Dagut delimited the exact scope applicable to the term as follows: "Every "metaphor" in the proper, narrow sense, is an 
individual flash of imaginative insight, ...which transcends the existing semantic limits of the language and thereby enlarges the hearers' or readers' emotional and intellectual awareness." (Dagut, 1976)

As we said before, words are not things, but symbols of things. Because all symbols are metaphors or metonyms replacing their objects, all words are metaphorical. At the same time, as a translator, words in context are neither things nor usually the same symbols as individual words, but components of a larger symbol of a clause or a sentence, even bigger unit. Therefore, to this extent language is a metaphorical web. In view of relationship between culture and language, we know that language is an important part of culture. Therefore, the meaning of metaphor is frequently culture-specific. As for translation, different languages in different cultures conceptualize and create symbols. In this sense, the translation of metaphor is in essence a cross-cultural transference.

Dagut assumed that all metaphors are "original" and "live". After analyzing a number of translations of metaphors from Hebrew into English, he got conclusion that: "What determines the translatability of a source language metaphor is not its "boldness" or "originality", but rather the extent to which the cultural experiences and semantic associations on which it draws are shared by speakers of the particular target language," (Dagut, 1976)

Later, Raymond (1987) thought that the translation is transferred with which to examine categories: lexicalized, conventional, and private. And he also pointed out that the status of a metaphor is not static but dynamic. As for translation theory, he claimed that the use of metaphor is related to its functional relevance to the communicative situation. What is more, he put forward three possible modes of metaphor translation: 1) Translation "sensu stricto" (or literal translation), when both source language "tenor" and source language "vehicle" are transferred into target language. 2) Substitution, and 3) Paraphrase. After van den Broeck's tightly structured theoretical treatment of the translation of metaphor, there appeared Peter Newmark's more pragmatic approach. He gave the definition of metaphor as "any figurative expression; the transferred sense of a physical word; the personification of an abstraction; the application of a word or collocation to what it does not literally denote, i.e., to describe one thing in terms of another." What is more, he argues that metaphor may be "single" (one word) or "extended" (a collocation, an idiom, a sentence, a proverb, an allegory, a complete imaginative text) and it can be divided into six types: dead, cliché, stock, adapted, recent, and original.

\section{Barriers in Metaphor Translation}

As we see, different cultures hold different knowledge, experience and beliefs, etc. Intercultural translation becomes difficult and complex consequently for it has turned into a kind of transfer and communication of culture. At the same time, metaphor bears high contents of culture. Therefore, metaphor translation becomes especially difficult and tough. In order to achieve the equivalents of culture in metaphor translation it is necessary to construe the barriers in metaphor translation.

Due to cultural differences when a translator has to translate the text with metaphors from one culture into another it is certain that a number of problems can appear. Of course it is easy to find that metaphor holds the same image and the same implied and associative meaning both in target language and source language. This phenomenon is called cultural overlap. It explains the fact that cultural universals are defined as the modes of behavior common to all cultures. For example, pigs are universally associated with uncleanness and stench. Thus, if we translate English sentence He is a pig into Chinese in literal way, Chinese readers can understand it without any problem because the cultural implicative meaning of pig is similar in both cultures.

However, most of time metaphors in different cultures have different images, and the same images hold different cultural connotations that are indeed the root of making translation difficulty.

Animal metaphors differ greatly from culture to culture. For example, in Chinese "She is a cat" means that the girl is meek and gentle. But in English its meaning is that the girl is evil-minded as the cat is usually deemed as the symbol of jinx. Another one can take dog as example. Dog is treated in western countries as a lovely pet, and there are some metaphorical expressions such as "love me, love my dog", "dog like devotion" because dog is viewed as a lovable pet and a faithful friend. On the contrary, dog usually has the derogatory sense in Chinese culture like the expressions “狗仗人势” (be a bully under the protection of a powerful person), “狗嘴里吐不出 象牙” (a filthy mouth can't utter decent language), etc. In English we hold "he is as poor as a church mouse", but Chinese says “他穷得象叫花子”; English says “ fishing in the air”, but Chinese says “水底捞月”, and so on.

Thus, the reason for mistakes often happening in intercultural metaphor translations is due to misunderstanding or lack of cultural background knowledge. For example:

“John can be relied on. He eats no fish and plays the game.” is often translated into “约翰可以依靠, 他不 
吃鱼, 还玩游戏。” In fact, its correct translation is “约翰可以依靠, 他既忠诚又正直。” In the sentence, "to eat no fish" comes from the contention between Protestants and Christians in England. Christians stipulated that only fish could be eaten on the Fast Day. After the Protestants overthrew the Christians, they refused to eat fish that day to show their clinging to Protestantism. Thus, "to eat no fish" means "loyal and faithful"; and "to play the game" originates item of sports and refers to "upright and fair". There are many examples like such mistake.

Therefore, another difficulty in metaphor translation comes from the reason that the English and Chinese metaphors hold the same semantic meaning, but have different cultural meanings. This also requires a suitable treatment to find suitable expression in target language.

Through the analysis it has been proved that metaphor translation is quite difficult and complex. There is a lot of misunderstanding appearing in the process of metaphor translation. Metaphor is quite different from literal language and its meaning is evasive and uncertain. What is more, metaphor is culture- specific, which deepens the difficulty of metaphor translation. So, it is quite necessary to achieve the task of the studies on the factors affecting the metaphor translation.

In a summary, language is the vehicle of culture and translation is the instrument for cultural exchange. Translation studies have been shifted from linguistic transfer to cultural transfer. As metaphor is fully saturated with the culture, it is of great significance for us to explore the cultural factors influencing on metaphor translation and then to seek for the appropriate principle and strategies in translating metaphor.

However, his theoretical approaches haven't been basically applied into practice to solve the translation of metaphor because of the obstacles above.

\section{Conclusion}

Through the analysis of the theories of metaphor translation mentioned above, we can get several points. Firstly, it is possible for a translator to deal with metaphor translation in practice. Secondly, when we translate metaphor, we should expand the scope of metaphor for there is not only "single" metaphor but also "extended" metaphor. Thirdly, cultural interference is an important obstacle in the process of metaphor translation. In the understanding of metaphors, different people have very different and even incompatible views on the same image. In brief, the best way of mastering metaphors is to get their meanings under the cultural context.

\section{References}

Bassnett, S., \& Lefevere, A. (2004). Constructing Cultures: Essays on Literary Translation. Shanghai: Shanghai Foreign Language Education Press.

Dagut, M. B. (1976). Can "Metaphor" Be Translated? In Bable, 22(1), 22-33. https://doi.org/10.1075/babel.22.1.05dag

Lakoff, G., \& Johnson, M. (1980). Metaphors we live by. Chicago: the University of Chicago Press.

Newmark, P. (2001a). A textbook of Translation. Shanghai: Shanghai Foreign Education Language Press.

Newmark, P. (2001b). Approaches to Translation. Shanghai: Shanghai Foreign Language Education Press.

Raymond, W. G., Jr. (1987). What does it mean to say a metaphor has been understood? In E. Robert (Ed.), Cognition and Symbolic Structures. Alex vPublishing House.

Richards, A. (1965). The Philosophy of Rhetoric. New York: Oxford University Press.

Hawkcs, T. (1992). Translated by Gao Bingzhong. On Metaphor. Beijing: Kunlun Press.

\section{Copyrights}

Copyright for this article is retained by the author(s), with first publication rights granted to the journal.

This is an open-access article distributed under the terms and conditions of the Creative Commons Attribution license (http://creativecommons.org/licenses/by/4.0/). 